\title{
Resistencia química del hormigón XXIV. Influencia de la adición de escoria a un cemento portland resistente al yeso. Estudio de la concentración iónica del sistema cemento 2/escoria-agua de mar artificial
}

\author{
DEMETRIO GASPAR-TEBAR y JOSE LUIS SAGRERA-MORENO \\ Drs. en Ciencias Quimicas (IETCC/CSIC)
}

\begin{abstract}
$R E S U M E N$
En el presente trabajo, continuación de otros, se estudia la evolución de la cantidad de fase sólida formada en el agua de mar artificial ASTM D 1141-75 en donde han estado sumergidas las series de probetas $(1: 3)$ hechas con un cemento portland resistente al yeso (cemento $2<>P 450-Y$ ) y con las mezclas cemento 2 escoria $=85 / 15,65 / 35,40 / 60$ y 30/70, en peso, durante $56-90$ - 180 y 360 dias (periodos de conservación-ataque), en esta etapa, después del periodo de curado ( 1 día en cámara húmeda y 21 dias bajo agua potable filtrada). Asi mismo, se estudia la variación del $\mathrm{pH}$ y de la concentración de los iones $\mathrm{Ca}(\mathrm{II}), \mathrm{Mg}(\mathrm{II}), \mathrm{SO}_{4}(\mathrm{II})$ y $\mathrm{Cl}(\mathrm{I})$ de dicha agua de mar artificial ASTM, asi como el contenido de los iones $\mathrm{Ca}$ (II), $\mathrm{Mg}$ (II) y $\mathrm{SO}_{4}$ (II) de las mencionadas fases sólidas. La composición estructural de dichas fases sólidas y de la fracción enriquecida extraida de la probetas de mortero se determinó por DRX; de ello se dió cuenta en (3).
\end{abstract}

En los casos estudiados se ha puesto de manifiesto que se produce un aumento de la concentración de Ca (II) en la disolución y del valor del $\mathrm{pH}$, una disminución del contenido de $\mathrm{Mg}(\mathrm{II}), \mathrm{SO}_{4}(\mathrm{II})$ y $\mathrm{Cl}(\mathrm{I})$, así como la formación de una nueva fase sólida, que son función de la mezcla utilizada para fabricar las mencionadas series de probetas y del tiempo de conservación-ataque. Por otra parte, se ha probado que la evolución de los contenidos de Ca (II) y de $\mathrm{Mg}$ (II) están intimamente ligados; cuando el del primero aumenta, el del segundo disminuye y viceversa, existiendo un punto que corresponde al equilibrio iónico $\mathrm{Ca}(I I) \rightleftharpoons \mathrm{Mg}$ (II)

Las cantidades de Ca (II) en la disolución y en la nueva fase sólida, procedentes de los compuestos del cemento hidratado disueltos, experimentan un incremento según lo hace el tiempo de conservación-ataque de cada serie de probetas hechas con una mezcla cemento 2/escoria y disminuyen bruscamente conforme lo hace el contenido de cemento 2 en la mencionada mezcla. $\mathrm{Si}$, además, se tiene en cuenta el contenido de Ca (II)

\section{$S U M M A R Y$}

This work, which follows on from previous ones, studies the development of the solid-stage quantity formed in ASTM D 1141-75 artificial sea-water, in which the series of samples of mortar ( $1: 3)$, made up of a portland cement resistant to sulfate (cement $2<>P 450-Y$ ) and the mixtures: cement $2 /$ slag $=85 / 15,65 / 35,40 / 60$ and $30 / 70$, in weight, were submerged for periods of 56,90 , 180 and 360 days (conservation-attack periods) at this stage. This took place after the curing period (1 day in a humid chamber and 21 days submerged in filtered drinking water). The change in the $\mathrm{pH}$ value and the concentration of $\mathrm{Ca}(\mathrm{II}), \mathrm{Mg}$ (II), $\mathrm{SO}_{4}(\mathrm{II})$ and $C l(I)$ ions in this ASTM artificial seawater are likewise studied, as are the content of Ca (II), Mg (II) and $\mathrm{SO}_{4}$ (II) ions from the aforementioned solid stages. The structural composition of these solid stages and of the enriched fraction from the samples of mortar was determined by XRD; an account of this was given in (3).

In the cases under study it has been shown that an increase occurs in the concentration of $\mathrm{Ca}$ (II) during dissolution and in the $\mathrm{pH}$ value, the $\mathrm{Mg}$ (II), $\mathrm{SO}_{4}$ (II) and $C l(I)$ content is reduced and a new solid stage is formed, these being the function of the mixture used for making the series of samples mentioned and of the conservation-attack period. Furthermore, it has been proved that the evolution in the Ca (II) and $\mathrm{Mg}$ (II) content is closely linked; when evolution in the first increases, that of the second decreases and vice-versa, there being a point which corresponds to the $C a(I I) \rightleftharpoons M g(I I)$ ionic balance.

Quantities of Ca (II) in to the dissolution and in the new solid stage, from compounds of dissolved, hydrated cement, show an increase in keeping in acordance with the conservation-attack period of each serie of samples made up of a cement 2/slag mixture, and decrease sharply in accordance with the reduction of cement 2 content in the aforementioned mixture. If, moreover, the Ca (II) content in the ASTM artificial sea-water is taken into account, the dissolving process of the Ca (II) 
del agua de mar artificial ASTM, el proceso de disolución de los compuestos de Ca (II) del cemento (valores medios) es aditivo.

El ion $M g$ (II) ha desaparecido, prácticamente, del agua de mar artificial ASTM en donde han estado sumergidas las series de probetas de mortero hechas con cemento 2 y con la mezcla que tiene $15 \%$ (en peso) de escoria; en estos medios ha precipitado como brucita.

En los restantes medios se encuentra en cantidades diversas según la mezcla utilizada en la fabricación de probetas.

Las mayores cantidades desaparecidas de los iones $\mathrm{SO}_{4}(\mathrm{II})$ y $\mathrm{Cl}$ (II) del agua de mar artificial corresponden a los medios en donde han estado las probetas de mortero hechas con cemento 2 y con las mezclas que tienen 15 y $35 \%$ de escoria, para el primero, y 35, 60 y $70 \%$ de escoria, para el segundo. En las nuevas fases sólidas se han detectado los iones $\mathrm{SO}_{4}$ (II) en cantidades menores de $0,07 \times 10^{-2}$ moles. compounds in the cement (average values) may be added.

The $M g$ (II) ion has virtually disappeared from the ASTM artificial sea-water, in which were submerged the series of mortar samples made up of cement 2 and of the mixture containing $15 \%$ slag, in weight; in these environments, it has precipitated in the form of brucite. In the other environments, it is found in various quantities, according to the mixture used in making up the samples.

The greatest quantities of $\mathrm{SO}_{4}(\mathrm{II})$ and $\mathrm{Cl}(\mathrm{I})$ ions that have disappeared from the artificial sea-water correspond to the environments containing the mortar samples made up of cement 2 and the mixtures with $15 \%$ and $35 \%$ slag for the firs, and $35 \%, 60 \%$ and $70 \%$ slag in the case of the second. In the new solid stages, $\mathrm{SO}_{4}$ (II) ions have been detected in quantities of less than $0.07 \times 10^{-2}$ moles.

\section{INTRODUCCION}

En otros trabajos anteriores (1) (2) (3) (4) se estudió:

a) La evolución que experimenta la resistencia quimica por el método de Koch-Steinegger y las modificaciones sufridas por las resistencias mecánicas a flexotracción de las probetas de mortero $(1: 3)$ de $1 \times 1 \times 6 \mathrm{~cm}$, hechas con el cemento protland industrial resistente al yeso (cemento $2<>$ P-450-Y), objeto del presente artículo, y con las mezclas cemento 2 /escoria $=85 / 15-65 / 35-40 / 60$ y $30 / 70$, en peso, sumergidas en agua potable filtrada $(*)$, unas series de 12 probetas, y en agua de mar artificial ASTM D 1141-75 (**), $800 \mathrm{~m} l$ por serie y por edad, otras series análogas, durante 56 - 90 - 180 y 360 días en esta etapa, después de haberlas curado 24 horas en un recinto saturado de humedad y, a continuación, bajo agua potable filtrada hasta 22 dias (1).

b) La composición estructural de las nuevas fases sólidas formadas en los medios de curado y de conservación (agua potable filtrada) (2), así como de conservación-ataque (agua de mar artificial) (3), en donde han estado sumergidas las mencionadas series de probetas de mortero.

c) La evolución de las características estructurales de la fracción enriquecida (cemento hidratado y cemento hidratado-atacado), extraída de uno de los prismas de mortero de cada serie de probetas del sistema cemento 2/escoria-agua potable filtrada (2) y del sistema cemento 2 /escoria-agua de mar artificial (3).

d) La variación de la concentración de los iones calcio y sulfato en los medios de curado y de conservación (agua potable filtrada), en dónde han estado sumergidas las diversas series de probetas de mortero, así como de las fases sólidas formadas, y la evolución del $\mathrm{pH}$ de dichos medios (4).

En el presente artículo, continuación de los anteriores y que se ampliará con otros, se estudia la variación de la concentración de los iones calcio, magnesio, sulfato y cloruro del agua de mar

(*) Sistema: cemento $2 /$ escoria-agua potable filtrada.

(**) Sistema: cemento 2/escoria-agua de mar artificial. 
artificial (ASTM D 1141-75) en donde han estado sumergidas las diversas series de probetas de mortero, asi como de las fases sólidas formadas (los tres primeros); así mismo, se estudia la evolución del $\mathrm{pH}$ de dichos medios y de las cantidades de las nuevas fases sólidas.

\section{PARTE EXPERIMENTAL}

En el agua de mar artificial (ASTM D 1141-75) en donde han estado sumergidas las distintas series de probetas de mortero $(1: 3)$ hechas con cemento 2 y con las mezclas cemento $2 /$ escoria $=85 / 15-65 / 35-40 / 60$ y 30/70 (en peso), una vez separada la nueva fase sólida formada como se señaló en (5), se ha determinado el contenido de los iones $\mathrm{Ca}$ (II) y $\mathrm{Mg}$ (II) complexométricamente con EDTA, el de los iones $\mathrm{SO}_{4}$ (II) gravimétricamente al estado de sulfato de bario, el de los iones $\mathrm{Cl}$ (I) volumétricamente por el método de Mohr y el valor del $\mathrm{pH}$ por medio de un $\mathrm{pH}$-metro, marca crison, modelo 501. Cada serie de probetas se ha sumergido en $800 \mathrm{~m} l$ de agua de mar artificial ASTM durante cada uno de los periodos de tiempo (56 - 90 - 180 y 360 días, en esta etapa).

En la nueva fase sólida, una vez separada (5) y puesta en disolución por ataque con una disolución de ácido clorhídrico $(1+1)$, se ha determinado, como se señala en el párrafo anterior, el contenido de los iones $\mathrm{Ca}$ (II), $\mathrm{Mg}$ (II) y $\mathrm{SO}_{4}$ (II).

De los materiales utilizados (cemento 2, escoria, arena, agua de mar artificial y agua potable filtrada) y características, de la técnica operatoria seguida para preparar las mezclas cemento 2 /escoria, así como para curar y conservar las probetas de mortero $(1: 3)$ de las diversas series en agua potable filtrada y en agua de mar artificial se dió cuenta en (1).

\section{RESULTADOS Y DISCUSION}

En la tabla 1 se encuentran las cantidades de las nuevas fases sólidas formadas en los medios (agua de mar artificial ASTM D 1141-75) en donde han estado sumergidas las diversas series de probetas hechas con las mezclas cemento 2 /escoria $=100 / 0-85 / 15-65 / 35-40 / 60$ y $30 / 70$ (en peso), durante $56-90-180$ y 360 dias, asi como los compuestos identificados por DRX, los valores del $\mathrm{pH}$ y las cantidades de $\mathrm{Ca}$ (II), $\mathrm{Mg}$ (II), $\mathrm{SO}_{4}$ (II) y $\mathrm{Cl}$ (I) en dichos medios. Además, se incluyen los contenidos de $\mathrm{Ca}$ (II), $\mathrm{Mg}$ (II) y $\mathrm{SO}_{4}$ (II) de las mencionadas fases sólidas.

En las figuras 1 a 11 , que se discuten en los apartados siguientes, se han representado dichos valores en función de la edad (tiempo de conservación-ataque) y de la mezcla cemento 2/escoria utilizada para fabricar las mencionadas series de probetas de mortero.

\subsection{Evolución de la cantidad de fase sólida}

En las figuras 1 y 2 se ha representado la cantidad de fase sólida formada, en los medios mencionados anteriormente, para las series de probetas hechas con una misma mezcla en función del tiempo de conservación-ataque, en la primera, y para cada edad en función de la mezcla utilizada para fabricar las distintas series de probetas, en la segunda, en donde puede observarse que dicha cantidad de fase sólida es:

a) función del tiempo de conservación-ataque para cada mezcla. Por regla general, la mencionada cantidad de fase sólida aumenta conforme lo hace la edad; en el caso de la serie hecha con cemento 2 sin adición de escoria permanece, prácticamente, constante a partir de 90 dias (figura 1), 
b) función de la mezcla utilizada en la fabricación de las probetas de mortero, disminuyendo para cada edad conforme lo hace la cantidad de cemento en dicha mezcla (figura 2), excepto para la serie hecha con cemento $2 /$ escoria $=85 / 15$, en peso, sumergida durante 360 dias, que es la mayor.

T ABLA 1

Sistema: cemento 2/escoria-agua de mar artificial ASTM Evolución de la fase sólida formada, del $\mathrm{pH}$ y de los contenidos de $\mathrm{Ca}(\mathrm{II}), \mathrm{Mg}(\mathrm{II}), \mathrm{SO}_{4}$ (II) y $\mathrm{Cl}(\mathrm{I})$.

Agua de mar ASTM (D 1141-75), contenidos en $800 \mathrm{ml}$ de:

$$
\begin{aligned}
& \mathrm{Ca}(\mathrm{II})=1,04 \times 10^{-2} \text { moles } \\
& \mathrm{Mg}(\mathrm{II})=4,43 \times 10^{-2} \text { moles } \\
& \mathrm{SO}_{4}(\mathrm{II})=2,44 \times 10^{-2} \text { moles } \\
& \mathrm{Cl}(\mathrm{I})=44,2 \times 10^{-2} \text { moles, } y \\
& \mathrm{pH}=6,5
\end{aligned}
$$

\begin{tabular}{|c|c|c|c|c|c|c|c|c|c|c|c|c|c|c|}
\hline \multirow{2}{*}{$\begin{array}{c}\text { Mezcla: } \\
\text { cemento 1/ } \\
\text { escoria } \\
\text { (en peso) }\end{array}$} & \multirow{2}{*}{$\begin{array}{l}\text { Edad } \\
\text { dias }\end{array}$} & \multicolumn{2}{|c|}{ Fase sólida } & \multirow{2}{*}{$\begin{array}{c}\text { Diso- } \\
\text { lución } \\
\text { pH }\end{array}$} & \multicolumn{3}{|c|}{ Ca (II), moles $\times 10^{-2}$} & \multicolumn{3}{|c|}{$\operatorname{Mg}($ II $)$, moles $\times 10^{-2}$} & \multicolumn{3}{|c|}{$\mathrm{SO}_{4}(1 \mathrm{II})$, moles $\times 10^{-2}$} & \multirow{2}{*}{$\begin{array}{l}\begin{array}{c}\mathrm{Cl}(\mathrm{I}) \\
\text { moles } \times \\
\times 10^{-2}\end{array} \\
\begin{array}{c}\text { Diso- } \\
\text { lución }\end{array}\end{array}$} \\
\hline & & g & DRX & & $\begin{array}{l}\text { Diso- } \\
\text { lución }\end{array}$ & $\begin{array}{c}\text { Fase } \\
\text { sólida }\end{array}$ & Suma & $\begin{array}{l}\text { Diso- } \\
\text { lución }\end{array}$ & $\begin{array}{c}\text { Fase } \\
\text { sólida }\end{array}$ & Suma & $\begin{array}{l}\text { Diso- } \\
\text { lución }\end{array}$ & $\begin{array}{c}\text { Fase } \\
\text { sólida }\end{array}$ & Suma & \\
\hline \multirow{4}{*}{$100 / 0$} & 56 & 2,42 & $\mathrm{Cc} \uparrow-\mathrm{Ag}-\mathrm{B} \uparrow$ & 12,1 & 4,30 & 1.39 & 5,69 & n.d. & 1,26 & 1,26 & 1,52 & 0,04 & 1,56 & 43,3 \\
\hline & 90 & 3.29 & $\mathrm{Cc} \uparrow \cdot \mathrm{Ag}$ & 7,1 & 3.53 & 2,50 & 6,03 & 0,48 & 0,32 & 0,80 & 1,58 & 0,06 & 1,64 & 44,2 \\
\hline & 180 & 3,55 & $\mathrm{Cc} \uparrow-\mathrm{Ag}-\mathrm{B} \uparrow$ & 9,4 & 4,01 & 2,09 & 6.10 & 0.13 & 1,60 & 1,73 & 1,57 & 0,05 & 1,62 & 44,2 \\
\hline & 360 & 3,57 & $\mathrm{Cc} \uparrow-\mathrm{Ag}-\mathrm{B}$ & 12,3 & 5,07 & 2,50 & 7,57 & n.d. & 0.94 & 0,94 & 1,47 & 0,05 & 1,52 & 44,2 \\
\hline \multirow{4}{*}{$85 / 15$} & 56 & 1,80 & $\mathrm{Cc} \uparrow-\mathrm{Ag}-\mathrm{B}$ & 11,8 & 3.74 & 1,22 & 4.96 & n.d. & 0,55 & 0,55 & 1,45 & 0,04 & 1,49 & 43,1 \\
\hline & 90 & 1,82 & $\mathrm{Cc} \uparrow-\mathrm{B}$ & 10,0 & 3.58 & 1,60 & 5,18 & 0,08 & 0,04 & 0.12 & 1,35 & 0.04 & 1,39 & 43,8 \\
\hline & 180 & 2,14 & $\mathrm{Cc} \uparrow-\mathrm{Ag}-\mathrm{B} \uparrow$ & 11,9 & 3,87 & 1,35 & 5,22 & n.d. & 0,78 & 0,78 & 1,22 & 0,03 & 1,25 & 43,7 \\
\hline & 360 & 4.17 & $\mathrm{Cc} \uparrow-\mathrm{Ag}-\mathrm{B}$ & 10,9 & 3.02 & 3.39 & 6,41 & n.d. & 0,50 & 0,50 & 0,88 & 0,07 & 0,95 & 44,2 \\
\hline \multirow{4}{*}{$65 / 35$} & 56 & 0,98 & $\mathrm{Cc} \uparrow-\mathrm{Ag}$ & 9,2 & 3,21 & 0,83 & 4,04 & 0,18 & 0,02 & 0,20 & 1,53 & 0,03 & 1,56 & 42,1 \\
\hline & 90 & 1,23 & $\mathrm{Cc} \uparrow-\mathrm{Ag}$ & 7,5 & 3,09 & 1,02 & 4,11 & 0,14 & 0,01 & 0,15 & 1,74 & 0,03 & 1,77 & 43,9 \\
\hline & 180 & 1,51 & $\mathrm{Cc} \uparrow-\mathrm{Ag}$ & 8,1 & 2,81 & 1,24 & 4,05 & 0,11 & 0,07 & 0,18 & 1,31 & 0,04 & 1,35 & 42,9 \\
\hline & 360 & 2,51 & $\mathrm{Cc} \uparrow-\mathrm{Ag} \uparrow$ & 8,3 & 2,53 & 2,18 & 4,71 & 0,11 & n.d. & 0,11 & 1,23 & 0.04 & 1,27 & 43,7 \\
\hline \multirow{4}{*}{$40 / 60$} & 56 & 0,32 & $\mathrm{Cc}-\mathrm{Ag} \uparrow$ & 8,0 & 1,97 & 0,24 & 2.21 & 1,38 & 0,02 & 1,40 & 1,91 & n.d. & 1,91 & 41,5 \\
\hline & 90 & 0,67 & $\mathrm{Cc}-\mathrm{Ag} \uparrow$ & 7,8 & 2,21 & 0,56 & 2,77 & 0,80 & 0,02 & 0,82 & 1,87 & $0,00_{6}$ & 1,88 & 42,2 \\
\hline & 180 & 1,07 & $\mathrm{Cc} \uparrow-\mathrm{Ag}-\mathrm{B}$ & 7,8 & 1,95 & 1,05 & 3,00 & 1,06 & 0,13 & 1,19 & 1,88 & n.d. & 1,88 & 43,4 \\
\hline & 360 & 1.72 & $\mathrm{Cc}-\mathrm{Ag} \uparrow$ & 7,9 & 1,89 & 1,38 & 3,27 & 1,41 & 0,10 & 1,51 & 1,97 & 0,01 & 1,98 & 43,7 \\
\hline \multirow{4}{*}{$30 / 70$} & 56 & 0,42 & $\mathrm{Cc}-\mathrm{Ag} \uparrow$ & 7,9 & 1,60 & 0,36 & 1,96 & 2,10 & 0,01 & 2,11 & 2,09 & n.d. & 2,09 & 42,0 \\
\hline & 90 & 0.52 & $\mathrm{Cc}-\mathrm{Ag} \uparrow$ & 7,9 & 1,70 & 0,42 & 2,12 & 2,13 & 0,03 & 2,16 & 2,16 & n.d. & 2,16 & 42,4 \\
\hline & 180 & 0,71 & $\mathrm{Cc}-\mathrm{Ag} \uparrow$ & 7,7 & 1,49 & 0,60 & 2,09 & 2,14 & 0,02 & 2,16 & 2,10 & $0,00_{4}$ & 2,10 & 41,8 \\
\hline & 360 & 1,32 & $\mathrm{Cc}-\mathrm{Ag} \uparrow$ & 7,8 & 1,58 & 1,03 & 2,61 & 2,46 & 0,08 & 2,54 & 2,41 & $0,00_{7}$ & 2,42 & 43,9 \\
\hline
\end{tabular}

n.d. = no detectado; $\mathrm{Cc}=$ Calcita; $\mathrm{Ag}=$ Aragonito; $\mathrm{B}=$ Brucita.

En la mencionada fase sólida se han identificado por difracción de rayos X (3) los picos de los siguientes compuestos cristalinos brucita, calcita y aragonito.

Los picos de la brucita se han detectado en los DRX de las fases sólidas formadas en el agua de mar artificial en donde han estado sumergidas las series de probetas hechas con cemento 2 
(excepto para $t=22+90$ días) y con la mezcla cemento $2 /$ escoria $=85 / 15$, en peso, para todas las edades y $40 / 60$, en peso, para $t=22+180$ días.

Los picos de la calcita, con intensidad variable, se han detectado en los DRX de todas las nuevas fases sólidas (para todas las edades), así como los del aragonito (excepto en el diagrama correspondiente a la fase formada en el medio en donde han estado las probetas de mortero hechas con la mezcla cemento $2 /$ escoria $=85 / 15$, en peso, para $t=22+90$ días).
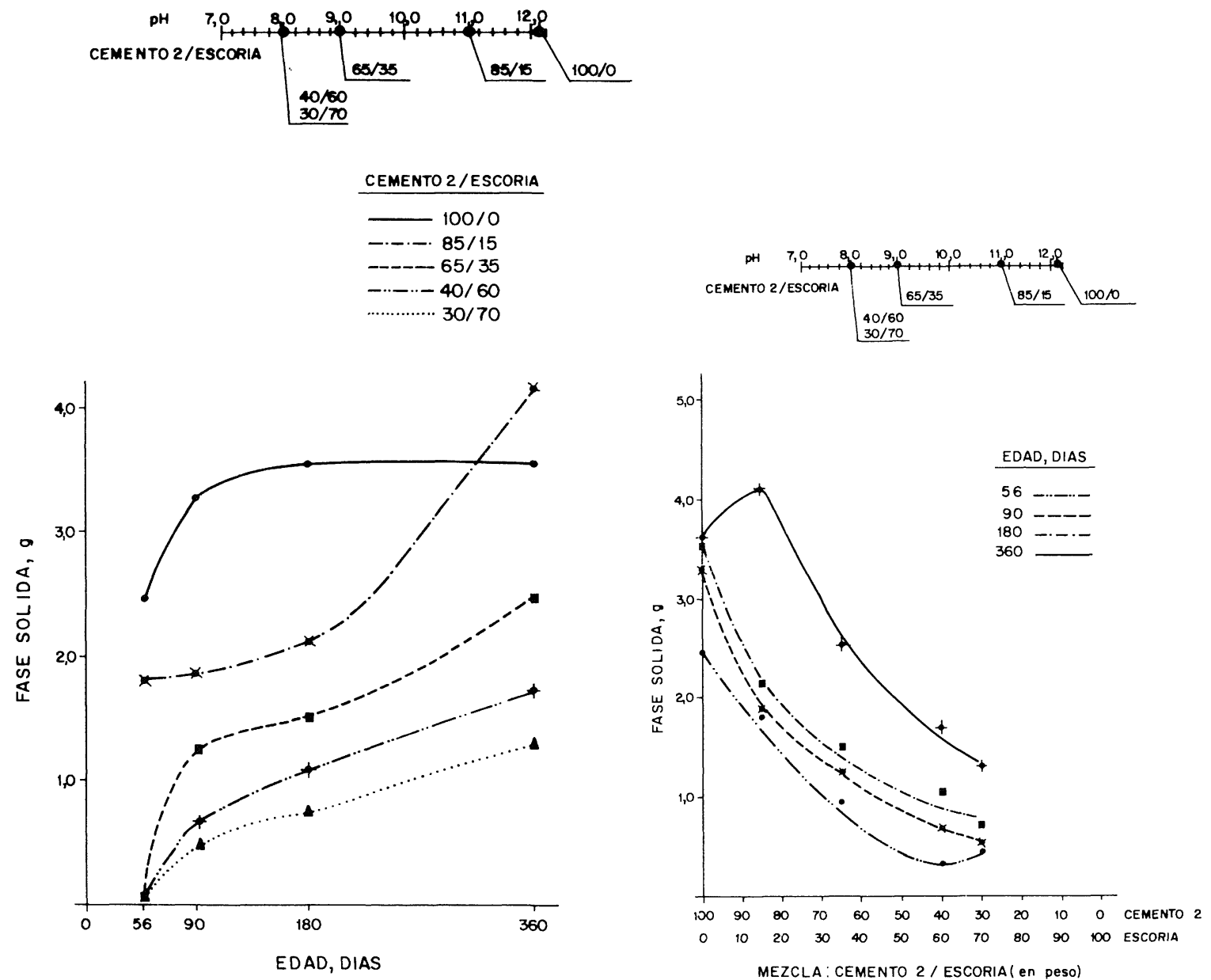

Fig. 1.-Sistema: cemento 2/escoria-agua de mar artificial ASTM. Evolución de la cantidad de fase sólida y del $\mathrm{pH}$.

Fig. 2.-Sistema: cemento 2/escoria-agua de mar artificial ASTM. Evolución de la cantidad de fase sólida y del $\mathrm{pH}$.

La máxima intensidad de los picos de la calcita, análoga entre si, es la correspondiente a los DRX de las fases sólidas formadas en el agua de mar artificial ASTM en donde han estado sumergidas, durante las cuatro edades, las series de probetas de mortero $(1: 3)$ fabricadas con cemento 2 y con las mezclas cemento $2 /$ escoria $=85 / 15$ y $65 / 35$, en peso; la mínima intensidad, para todas las edades, corresponde a los diagramas de rayos $\mathrm{X}$ de la fase sólida que aparece en el medio en donde han estado las probetas elaboradas con la mezcla cemento $2 /$ escoria que tiene el menor contenido de cemento 2 ( $30 \%$, en peso). Por el contrario, la máxima intensidad de los picos del aragonito se encuentra en los DRX que presentan la minima para los picos de la calcita y viceversa.

\subsection{Evolución del $\mathbf{p H}$}

En las figuras 1 y 2 se señalan los valores más frecuentes del $\mathrm{pH}$ en los medios de 
conservación-ataque para los distintos casos estudiados del sistema cemento 2/escoria-agua de mar artificial.

Por regla general, el valor del $\mathrm{pH}$ del agua de mar artificial, en donde han estado sumergidas las diversas series de probetas de mortero hechas con cemento 2 y con la mezcla cemento 2 /escoria $=85 / 15$, en peso, para las cuatro edades, es superior a 9 e inferior a 12,3 y el correspondiente a las restantes series de probetas es superior a 7,5 e inferior a 9,5.

El pH del agua de mar artificial ASTM D 1141-75 es 6,5.

\subsection{Evolución del contenido de Ca (II)}

En las figuras 3 y 4 se ha representado el contenido de $\mathrm{Ca}$ (II) disuelto [Ca (II) en la fase sólida $+\mathrm{Ca}$ (II) en la fase líquida] procedente - de un modo especial- del $\mathrm{Ca}(\mathrm{OH})_{2}$ del cemento hidratado, en función del tiempo de conservación-ataque para las series de probetas de mortero hechas con una mezcla, primera figura, y en función de la mezcla cemento 2 /escoria utilizada para fabricar las diversas series de probetas de mortero $(1: 3)$ para cada edad (tiempo de conservación-ataque), en la segunda figura.

En la figura 3 se aprecia que las cantidades de $\mathrm{Ca}$ (II) $<>\mathrm{Ca}(\mathrm{OH})_{2}$ disuelto, que se encuentra en la disolución y en la nueva fase sólida, aumentan conforme lo hace el tiempo de conservación-ataque, experimentando las diversas series de probetas de mortero sumergidas durante 56 y 360 dias los incrementos que se incluyen en la tabla 2 .

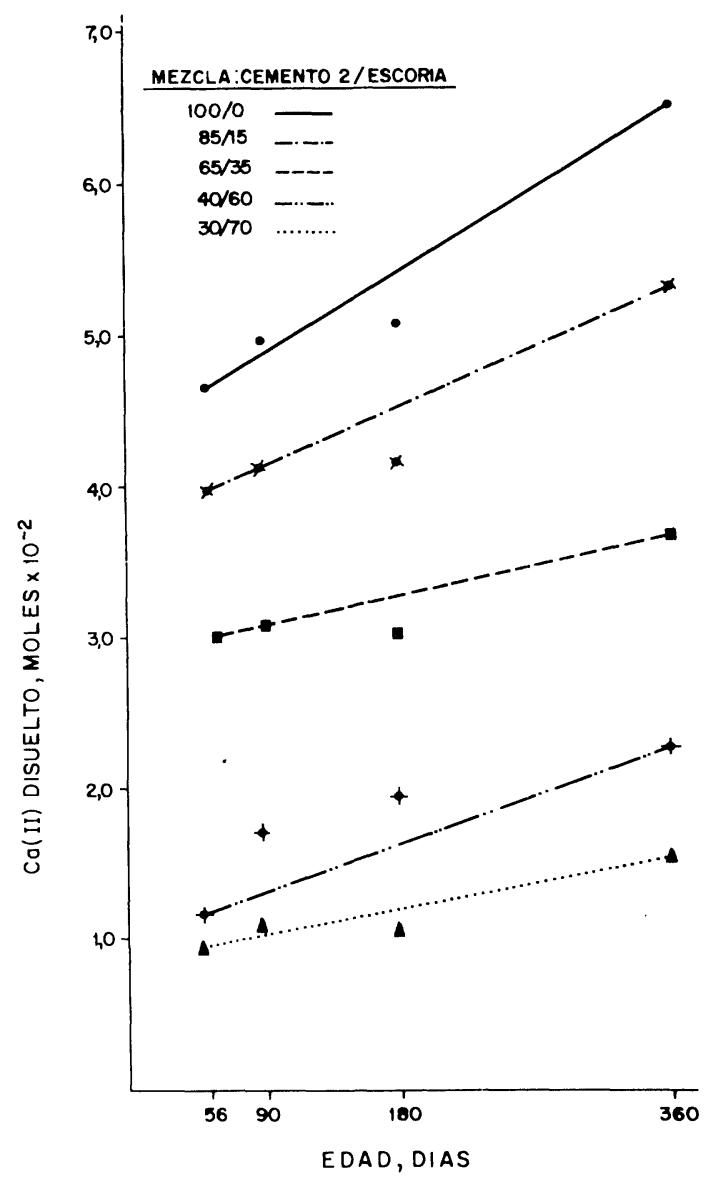

Fig. 3.--Sistema: cemento 2/escoria-agua de mar artificial ASTM. Evolucion del contenido de Ca (II) disuelto.

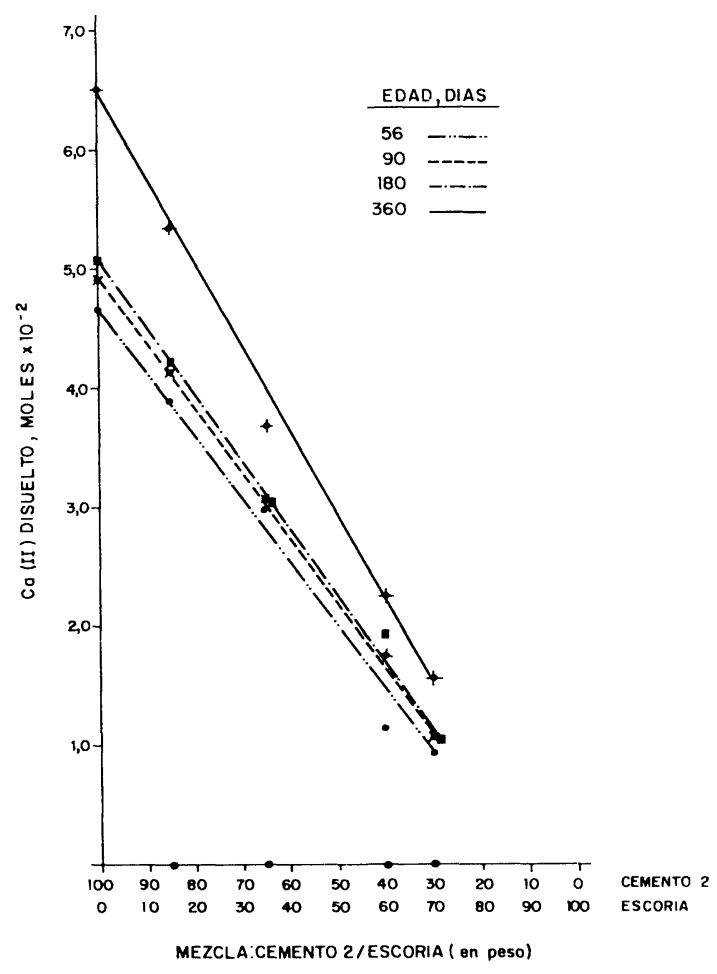

Fig. 4.--Sistema: cemento 2/escoria-agua de mar artificial ASTM. Evolución del contenido de Ca (II) disuelto. 
T ABLA 2

Sistema: cemento 2/escoria-agua de mar artificial ASTM. Evolución del contenido de Ca (II) disuelto, que se encuentra en la fase líquida y en la fase sólida, en moles $\times 10^{-2}$

\begin{tabular}{|c|c|c|c|c|}
\hline $\begin{array}{c}\text { Mezcla: } \\
\text { cemento 2 }\end{array}$ & \multicolumn{2}{|c|}{ Ca (II) disuelto, moles $\times \mathbf{1 0}^{-\mathbf{2}}$} & \multirow{2}{*}{ Escoria } \\
\cline { 2 - 3 } (en peso) & $\mathbf{5 6}$ dias & $\mathbf{3 6 0}$ dias & & \\
\hline \multirow{2}{*}{$100 / 0$} & 4,65 & 6,53 & 1,88 & 40,4 \\
$85 / 15$ & 3,92 & 5,37 & 1,45 & 36,9 \\
$65 / 35$ & 3,00 & 3,67 & 0,67 & 22,3 \\
$40 / 60$ & 1,17 & 2,23 & 1,06 & 90,6 \\
$30 / 70$ & 0,92 & 1,57 & 0,65 & 70,6 \\
\hline
\end{tabular}

En la figura 4 se observa que, para cada edad, la cantidad de $\mathrm{Ca}$ (II) $<>\mathrm{Ca}(\mathrm{OH})_{2}$ disuelto, que se encuentra en la disolución y en la fase sólida formada en cada caso, disminuye brúscamente según lo hace el contenido de cemento 2 en la mezcla utilizada para fabricar las distintas series de probetas de mortero. Si, además, del Ca (II) mencionado se considera el que existe en el agua de mar artificial ASTM $\left(1,04 \times 10^{-2}\right.$ moles en los $\left.800 \mathrm{ml}\right)$-es decir, el $\mathrm{Ca}$ (II) presente en la fase líquida más el Ca (II) que se encuentra en la fase sólida (figura 5) - se aprecia que para la edad de conservación-ataque correspondiente al primer periodo de tiempo (56 dias) la línea recta que une los distintos puntos de las diversas mezclas atraviesa al eje de abscisas en el punto que representa la mezcla cemento $2 /$ escoria $=0 / 100$, en peso, (cuando no existe cemento 2). En este caso, se considera que se trata de un fenómeno en el cual se pone en juego la cantidad de $\mathrm{Ca}$ (II) que corresponde a la del cemento 2 de la mezcla cemento 2/escoria utilizada para fabricar las distintas series de probetas de mortero, como se aprecia en la tabla 3 , en donde figuran las cantidades experimentales de dicho $\mathrm{Ca}$ (II) y las calculadas a partir del $\mathrm{Ca}$ (II) puesto en juego

T A B LA 3

Sistema: cemento 2/escoria-agua de mar artificial ASTM. Cantidades de Ca (II) en la fase líquida y en la fase sólida, en moles $\times 10^{-2}$

\begin{tabular}{|c|c|c|}
\hline \multicolumn{1}{l|}{$\begin{array}{l}\text { Mezcla: } \\
\text { cemento 2 }\end{array}$} & \multicolumn{2}{|c|}{ Ca (II), moles $\times \mathbf{1 0}^{-2}$} \\
\cline { 2 - 3 } escoria & calculado & experimental \\
\hline $100 / 0$ & 5,69 & 5,69 \\
$85 / 15$ & 4,84 & 4,96 \\
$65 / 35$ & 3,70 & 4,04 \\
$40 / 60$ & 2,28 & 2,21 \\
$30 / 70$ & 1,71 & 1,96 \\
\hline
\end{tabular}

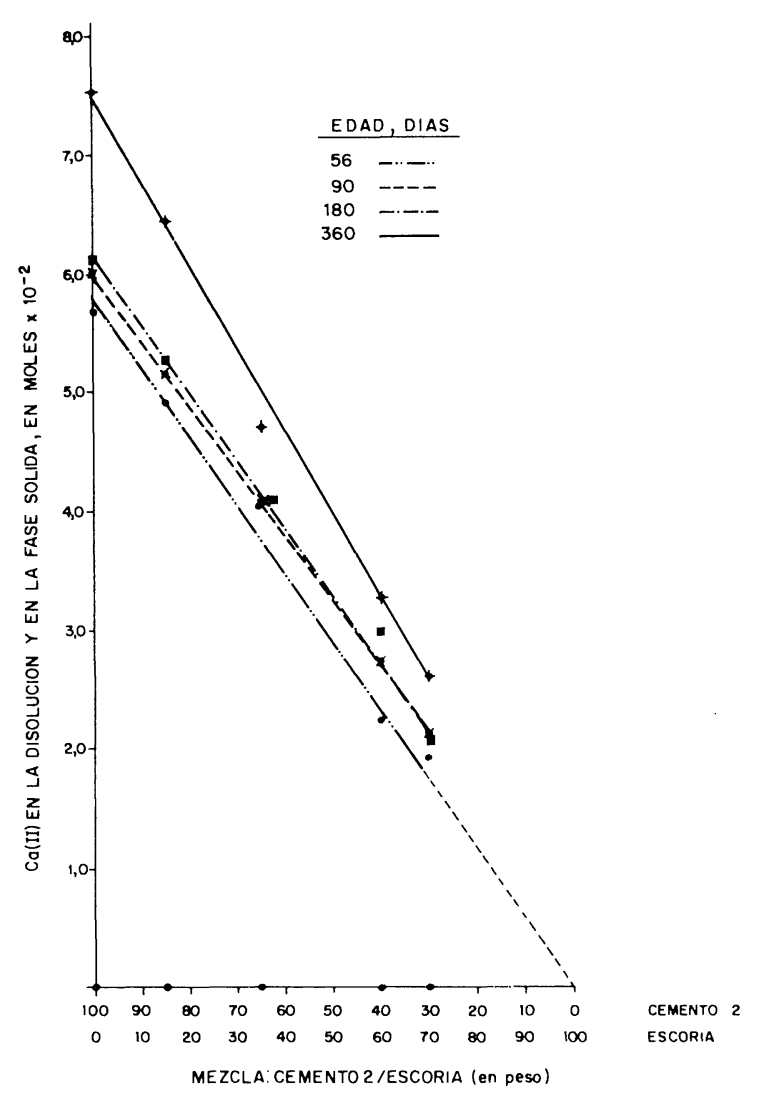

Fig. 5.--Sistema: cemento 2/escoria-agua de mar artificial ASTM. Evolución del contenido de Ca (II) total. 
en el sistema parcial cemento 2/escoria (100/0)-agua de mar artificial ASTM, para $t=22+56$ dias, teniendo en cuenta la cantidad de cemento 2 en las mezclas.

Si se tiene en cuenta la cantidad de Ca (II) puesta en juego para todas las edades, con relación a la primera, se aprecia que existe un incremento para cada mezcla, que va disminuyendo conforme aumenta la cantidad de escoria de dichas mezclas.

\subsection{Evolución del contenido de $\mathrm{Mg}$ (II)}

En las figuras 6 y 7 se ha representado el contenido de $\mathrm{Mg}$ (II) en el agua de mar artificial, en donde han estado sumergidas las diversas series de probetas de mortero, más en la nueva fase sólida que se ha formado en dichos medios, en función de la edad (primera figura) y de la mezcla cemento 2 /escoria utilizada para fabricar las mencionadas series de probetas (segunda figura).

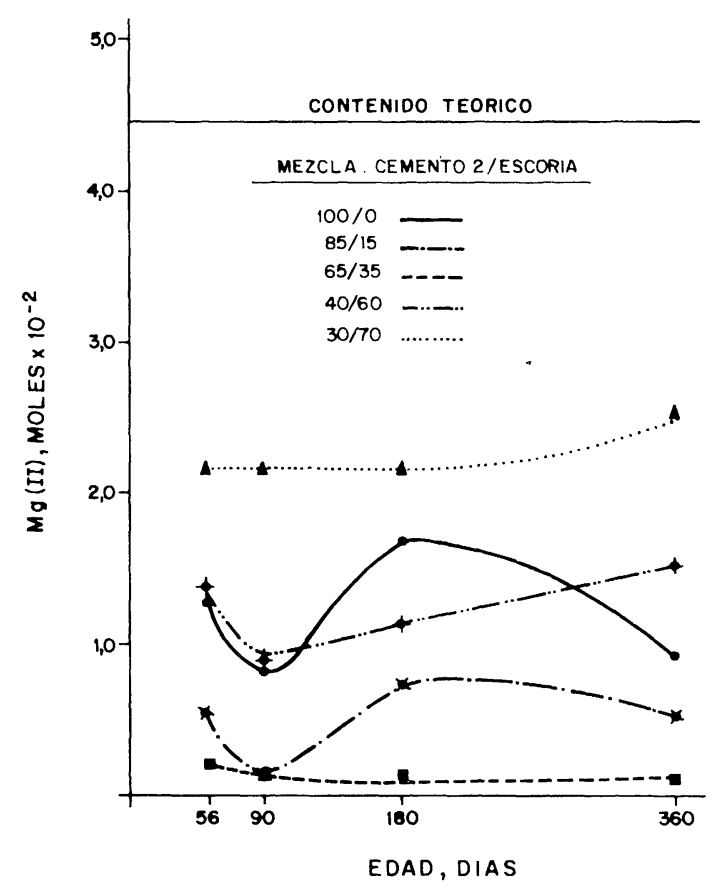

Fig. 6.- Sistema: cemento 2/escoria-agua de mar artificial ASTM. Evolución del contenido de $\mathrm{Mg}$ (II) en la disolución más en la fase solida.

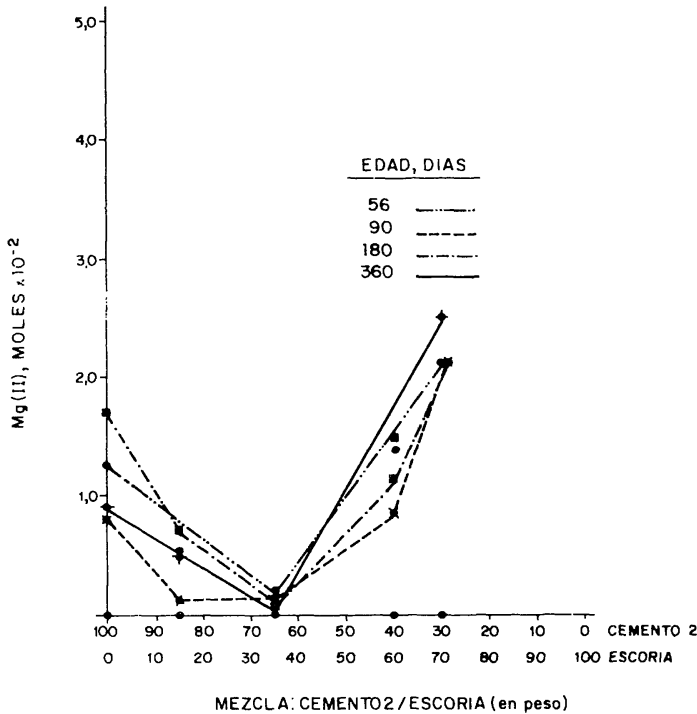

Fig. 7.--Sistema: cemento 2/escoria-agua de mar artificial ASTM. Evolución del contenido de Mg (II) en la disolución más en la fase solida.

El contenido de $\mathrm{Mg}$ (II) del agua de mar artificial ASTM $\left(4,43 \times 10^{-2}\right.$ moles $/ 800 \mathrm{~m} l$ por serie de probetas), en donde han estado sumergidas las diversas series de probetas de mortero, ha experimentado en todos los casos estudiados una disminución, que es función de la mezcla utilizada para fabricar las diversas series de probetas de mortero y del tiempo de conservaciónataque (tabla 1, fig. 6 y 7), que influyen, además, en las condiciones del medio modificando, de un modo especial, la concentración de los grupos $\mathrm{OH}(\mathrm{I})$.

El ion $\mathrm{Mg}$ (II) ha desaparecido, prácticamente, del agua de mar artificial ASTM en donde han estado sumergidas las series de probetas de mortero hechas con cemento $2 \mathrm{y}$ con la mezcla que tiene el menor contenido de escorias (15\%); dicho ion se ha detectado en los medios correspondientes a las edades $22+90$ dias, para ambos casos, y $22+180$ dias, para el primero.

En los medios (agua de mar artificial ASTM) en donde han estado las series de probetas hechas 
con la mezcla cemento $2 /$ escoria $=65 / 35$ (en peso), se encuentran cantidades comprendidas entre $0,11 \times 10^{2}$ y $0,18 \times 10^{-2}$ moles y con las mezclas que tienen los mayores contenidos de escoria ( 60 y $70 \%$, en peso) en cantidades iguales o superiores a $0,80 \times 10^{2}$ moles.

El ion $\mathrm{Mg}$ (II) también se ha detectado en las fases sólidas formadas en el agua de mar artificial ASTM, en donde han estado sumergidas las diversas series de probetas de mortero fabricadas con cemento 2 y con la mezcla cemento $2 /$ escoria $=85 / 15$ (en peso), en cantidades superiores a $0,90 \times 10^{-2}$ moles y a $0,45 \times 10^{-2}$ moles, respectivamente, excepto para 90 dias en ambos casos. Para los casos restantes, dichas cantidades, son menores de $0,15 \times 10^{-2}$ moles.

En las mencionadas fases sólidas, formadas en los medios en donde han estado las series de probetas de mortero hechas con cemento 2 y con la mezcla cemento $2 /$ escoria $=85 / 15$ (en peso), se han detectado por DRX (3) los picos del compuesto cristalino brucita. Asi mismo, en las fracciones enriquecidas extraidas de todas las series de probetas fabricadas con cemento 2 y con las mezclas cemento 2/escoria, sumergidas en agua de mar artificial ASTM durante los periodos de tiempo estudiados por el momento, se han detectado por DRX, entre otros, los picos del compuesto cristalino brucita (3).

En la tabla 1 y en la figura 6 se observa que la evolución de los contenidos de $\mathrm{Mg}$ (II) en las disoluciones (agua de mar artificial) en donde han estado sumergidas las probetas de mortero, más el que existe en las nuevas fases sólidas formadas en cada caso, en función del tiempo de conservación-ataque, se encuentra en un entorno comprendido entre $0,11 \times 10^{-2}$ moles y en $0,20 \times 10^{-2}$ moles y entre $2,11 \times 10^{-2}$ moles y $2,54 \times 10^{-2}$ moles para los medios en donde han estado las series de probetas hechas con las mezclas cemento $2 /$ escoria $=65 / 35$ y $30 / 70$ (en peso), respectivamente. En los medios en donde se han conservado-atacado las series fabricadas con las mezclas cemento $2 /$ escoria $=100 / 0-85 / 15$ y $40 / 60$ (en peso), dichas cantidades se encuentran comprendidas entre $0,80 \times 10^{2}$ moles y $1,73 \times 10^{2}$ moles, entre $0,12 \times 10^{-2}$ moles y $0,78 \times 10^{-2}$ moles y entre $0,82 \times 10^{-2}$ moles y $1,51 \times 10^{-2}$ moles, respectivamente.

Las cantidades de $\mathrm{Mg}$ (II) que existen en la disolución en donde han estado las series de probetas, junto con las de la fase sólida, disminuyen conforme lo hace la de cemento 2, para todas las edades, en las mezclas cemento 2 escoria empleadas para fabricar dichas series de probetas, hasta la mezcla que tiene $65 \%$ (en peso) de dicho cemento. En los medios en donde han estado las probetas hechas con las mezclas cemento $2 /$ escoria $=40 / 60$ y 30/70 (en peso), que tienen los menores contenidos de cemento 2, las cantidades de $\mathrm{Mg}$ (II) aumentan.

\subsection{Evolución del contenido de $\mathrm{SO}_{4}$ (II)}

El contenido de iones $\mathrm{SO}_{4}$ (II) en el agua de mar artificial ASTM D 1141-75 $\left(2,44 \times 10^{-2}\right.$ moles en $800 \mathrm{~m} l$ por serie de probetas), en donde han estado sumergidas las diversas series de probetas de mortero, ha experimentado en todos los casos estudiados una disminución que depende de la mezcla cemento 2/escoria utilizada en la fabricación de las diversas series de probetas de mortero y del tiempo de conservación-ataque (tabla 1, figuras 8 y 9). Los iones $\mathrm{SO}_{4}$ (II) se han detectado en el agua de mar artificial en cantidades comprendidas entre $0,88 \times 10^{2}$ moles y $2,41 \times 10^{-2}$ moles y en la nueva fase sólida en cantidades menores de $0,07 \times 10^{-2}$ moles; dichos iones se encuentran prácticamente, en estos casos, en la fase líquida.

En las fracciones enriquecidas extraidas de una probeta de las diversas series fabricadas con las distintas mezclas cemento 2/escoria estudiadas, sumergidas durante los mencionados periodos de tiempo en agua de mar artificial, se han detectado por DRX, entre otros, los picos del compuesto cristalino ettringita y, en determinados casos, los del yeso secundario (3); la intensidad de dichos picos depende de la mezcla cemento 2/escoria utilizada en la elaboración de las probetas de mortero. La mayor intensidad de los picos de la ettringita se presenta en los 
diagramas de las muestras correspondientes a las series de probetas hechas con cemento 2 y con las mezclas que tienen 15 y $35 \%$ de escoria; por el contrario, la menor intensidad, para cada edad, se encuentra en los DRX de las muestras extraidas de las probetas fabricadas con las mezclas que tienen los menores contenidos de cemento 2 (mezclas: cemento $2 /$ escoria $=40 / 60$ y $30 / 70$, en peso).

En las figuras 8 y 9 se ha representado la evolución del contenido de $\mathrm{SO}_{4}$ (II) en la disolución, más en la nueva fase sólida, en función del tiempo de conservación-ataque (primera figura) y de la mezcla cemento 2/escoria utilizada en la fabricación de las distintas series de probetas de mortero (segunda figura). En la figura 8 se aprecia que el contenido de iones $\mathrm{SO}_{4}$ (II) en el agua de mar artificial, en donde han estado sumergidas las series de probetas de mortero hechas con cemento 2 y con las mezclas cemento $2 /$ escoria $=40 / 60$ (en peso), permanece, a lo largo del tiempo, prácticamente constante, disminuyendo en los dos casos que corresponden a los medios en donde han estado las probetas elaboradas con las mezclas cemento $2 /$ escoria $=85 / 15$ y $65 / 35$ (en peso). En el caso restante (agua de mar artificial en donde se han sumergido las probetas fabricadas con la mezcla que tiene el mayor contenido de escoria, $70 \%$ ) experimenta un ligero incremento.

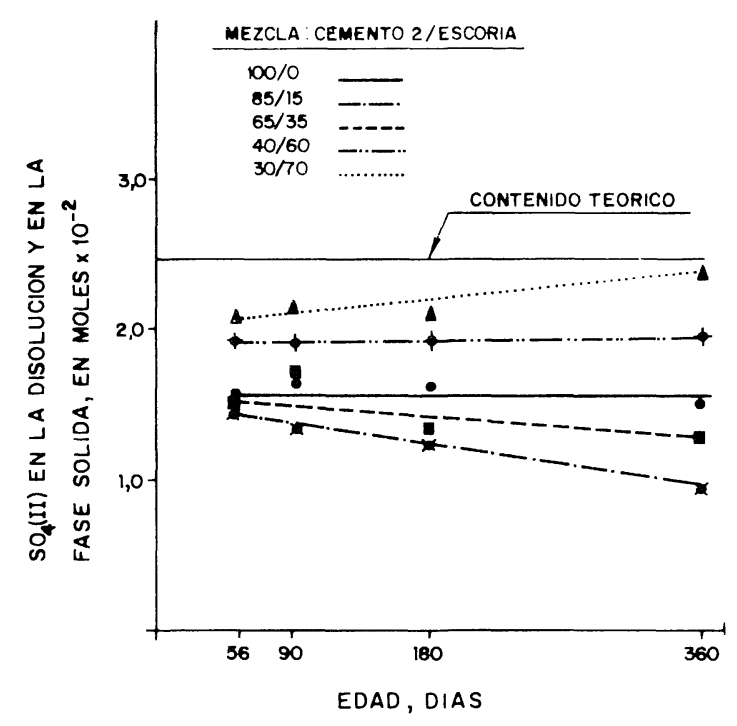

Fig. 8.--Sistema: cemento 2/escoria-agua de mar artificial ASTM. Fiolución del contenido de Mg (II) en la disolución mas en la fase solida.

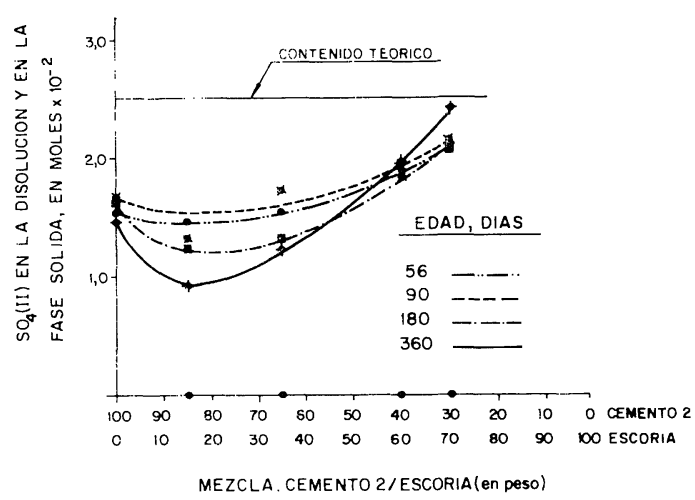

Fig. 9.- Sistema: eemento 2/escoria-agua de mar artificial ASTM. Evolución del contenido de $\mathrm{SO}_{4}$ (II) en la disolución más en la fase solida.

Las cantidades de $\mathrm{SO}_{4}$ (II), para cada edad, que existen en la disolución y en la nueva fase sólida son función de la mezcla cemento 2/escoria empleada en la fabricación de las series de probetas de mortero; dicho contenido disminuye en aquellos casos en donde han estado sumergidas las series de probetas hechas con las mezclas cemento $2 /$ escoria $=85 / 15$ y $65 / 35$, en peso, (figura 9).

Las cantidades desaparecidas de iones $\mathrm{SO}_{4}$ (II) del agua de mar artificial ASTM, fijadas por las probetas de mortero en donde han formado los compuestos correspondientes, depende de la mezcla cemento 2 /escoria utilizada para fabricar dichas probetas y del tiempo de conservaciónataque. Cuando las cantidades de escoria son altas (60 y $70 \%$, en peso), las correspondientes a los iones $\mathrm{SO}_{4}$ (II) son menores de $0,60 \times 10^{-2}$ moles, mientras que en los otros dos casos (mezclas con 15 y $35 \%$, en peso, de escoria) son menores de $1,50 \times 10^{-2}$ moles y mayores de $0,60 \times 10^{-2}$ moles. 


\subsection{Evolución del contenido de $\mathbf{C l}$ (I)}

En la tabla 1 se encuentran las cantidades de dichos iones $\mathrm{Cl}$ (I) en el agua de mar artificial ASTM en donde han estado sumergidas las diversas series de probetas de mortero, cantidades que se han representado en función del tiempo de conservación-ataque y de la mezcla utilizada para fabricar las mencionadas series de probetas de mortero en las figuras 10 y 11 , respectivamente.

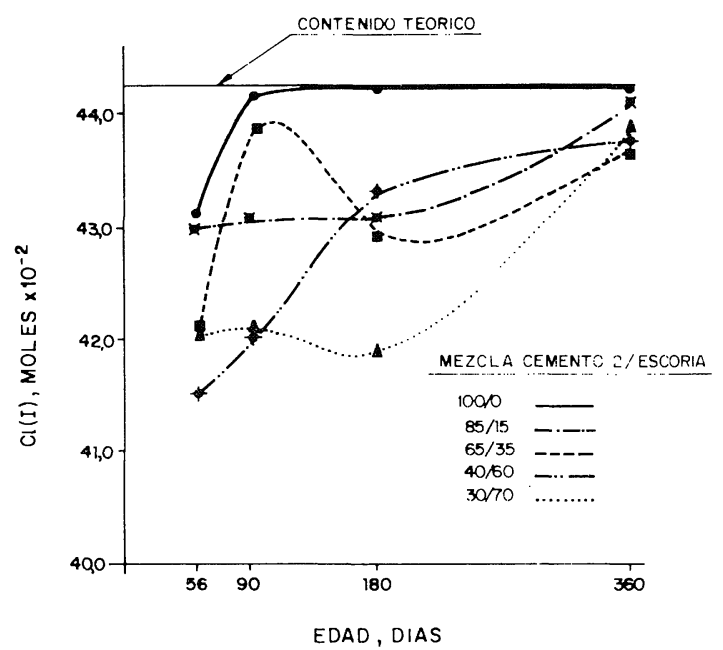

Fig. 10.--Sistema: cemento 2/escoria-agua de mar artificial ASTM. Evolucion del contenido de $\mathrm{Cl}$ (I) en la disolucion.

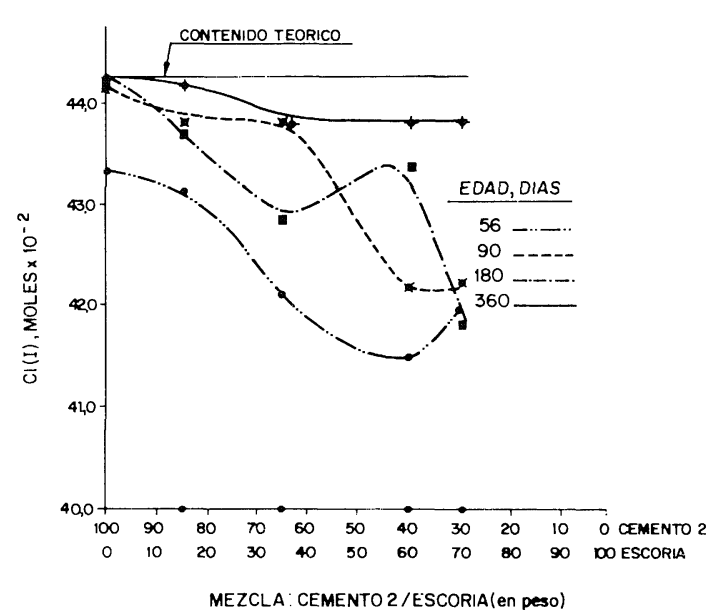

Fig. 11.- Sistema: cemento 2/escoria-agua de mar artificial ASTM. Evolucion del contenido de $\mathrm{Cl}$ (I) en la disolucion.

El contenido de $\mathrm{Cl}$ (I) del agua de mar artificial ASTM $\left(44,2 \times 10^{-2}\right.$ moles en $800 \mathrm{ml}$, por serie de probetas) ha disminuido en todos los casos, excepto para los medios en donde han estado sumergidas durante $90-180$ y 360 días las series de probetas de mortero hechas con cemento 2 y durante 360 dias las series elaboradas con la mezcla cemento $2 /$ escoria $=85 / 15$ (en peso). En los demás casos se encuentra comprendido dicho contenido entre $41,5 \times 10^{-2}$ moles y $43,9 \times 10^{-2}$ moles.

Dicho contenido de $\mathrm{Cl}$ (I) es función de la mezcla cemento 2/escoria utilizada en la fabricación de las series de probetas de mortero y del tiempo de conservación-ataque (figuras 10 y 11). Las cantidades mayores se presentan en los medios en donde han estado las series de probetas hechas con cemento 2 durante 90,180 y 360 dias, como se ha mencionado anteriormente; son del mismo orden que el contenido del agua de mar artificial.

En las fracciones enriquecidas, extraidas de una probeta de cada serie, sumergida en agua de mar artificial ASTM ( $800 \mathrm{~m} l$ por serie y por edad) durante los periodos de tiempo mencionados, se han identificado por DRX, entre otros, los picos del compuesto cristalino sal de Friedel (3), con intensidad variable, en los casos de las probetas fabricadas con las mezclas cemento $2 /$ escoria $=65 / 35.40 / 60$ y 30/70 (en peso); hechos que se corresponden, en gran parte, con la eliminación de iones $\mathrm{Cl}$ (I) en el agua de mar artificial ASTM en donde han estado las mencionadas probetas de mortero.

\section{INTERPRETACION DE RESULTADOS}

En el agua de mar artificial ASTM D 1141-75, en donde han estado sumergidas las diversas series de probetas de mortero $(800 \mathrm{~m} /$ por serie de 12 probetas y por edad) hechas con cemento 2 y con las mezclas cemento $2 /$ escoria $=85 / 15-65 / 35-40 / 60$ y 30/70 (en peso), se han 
producido una serie de fenómenos como son: formación de una nueva fase sólida que ha precipitado en el medio, incremento de la cantidad de $\mathrm{Ca}$ (II) y del $\mathrm{pH}$, y disminución del contenido de $\mathrm{Mg}$ (II), de $\mathrm{SO}_{4}$ (II) y de $\mathrm{Cl}$ (I).

El incremento de $\mathrm{Ca}$ (II), con relación al contenido de dicho ion en el agua de mar artificial $\left(1,04 \times 10^{-2}\right.$ moles $/ 800 \mathrm{ml}$ por serie de probetas y por edad $)$ es producido, fundamentalmente, por la disolución de parte del $\mathrm{Ca}(\mathrm{OH})_{2}$ formado, como consecuencia de las reacciones de hidratación de los compuestos del cemento $\left(\mathrm{C}_{3} \mathrm{~S}, \mathrm{C}_{2} \mathrm{~S}\right.$ y $\mathrm{CaO}$ libre), según:

$$
\stackrel{\mathrm{H}_{2} \mathrm{O} \text { mar }}{\mathrm{Ca}(\mathrm{OH})_{2} \text {. sólido } \rightleftharpoons \mathrm{Ca}(\mathrm{OH})_{2} \text {.disuelto } \rightleftharpoons \mathrm{Ca}(\mathrm{II})+2 \mathrm{OH}(\mathrm{I})}
$$

dando lugar, además, a un incremento de los iones $\mathrm{OH}$ (I) y, por consiguiente, del valor del $\mathrm{pH}$, llegando a alcanzar valores superiores a 12 .

La solubilidad, a $20^{\circ} \mathrm{C}$, del $\mathrm{Ca}(\mathrm{OH})_{2}$ en agua es $1,230 \mathrm{~g} / \mathrm{l}(6)<>1,66 \times 10^{-2} \mathrm{moles} / \mathrm{li}-$ tro $\left\langle>1,33 \times 10^{2}\right.$ moles en $800 \mathrm{ml}$. La cantidad de $\mathrm{Ca}(\mathrm{OH})_{2}$ disuelto es función del que se forma en las reacciones de hidratación que, a su vez, depende de la mezcla cemento 2/escoria empleada en la fabricación de las diversas series de probetas. Parte del $\mathrm{Ca}(\mathrm{OH})_{2}$ formado reacciona con la escoria para dar los compuestos de calcio correspondientes, como se señaló en (3).

EI equilibrio (A) se ve afectado, en este caso, por la presencia de los iones presentes en el agua de mar artificial ASTM no comunes, distintos del Ca (II), que no producen otras reacciones -EFECTO SALINO- y. además, por la existencia de otros iones o compuestos que dan lugar a reacciones de precipitación con los iones $\mathrm{Ca}$ (II) o con los iones $\mathrm{OH}$ (I) del mencionado equilibrio (A), como son:

$$
\begin{gathered}
\mathrm{Ca}(\mathrm{II})+2 \mathrm{OH}(\mathrm{I})+\mathrm{CO}_{2} \rightleftharpoons \mathrm{CaCO}_{3} \text {. sólido }+\mathrm{H}_{2} \mathrm{O} \\
\mathrm{Ca}(\mathrm{II})+\mathrm{SO}_{4}(\mathrm{II}) \stackrel{\mathrm{H}_{2} \mathrm{O}}{\rightleftharpoons} \mathrm{CaSO}_{4} \cdot 2 \mathrm{H}_{2} \mathrm{O} \\
\mathrm{Mg}(\mathrm{II})^{\circ}+2 \mathrm{OH}(\mathrm{I}) \rightleftharpoons \mathrm{Mg}(\mathrm{OH})_{2} \text {. sólido }
\end{gathered}
$$

que producen, en un grado determinado, la disminución de iones $\mathrm{Ca}$ (II) y $\mathrm{OH}$ (I) favoreciendo, asi mismo, la solubilidad del $\mathrm{Ca}(\mathrm{OH})_{2}$ y el avance de las reacciones de hidratación; estos fenómenos se han puesto de manifiesto en otros trabajos de los que se viene dando cuenta (7).

El pH del agua de mar artificial ASTM $(6,5)$ alcanza valores superiores a 12 en los medios en donde han estado las series de probetas hechas con cemento 2, a 10 e inferiores a 12 en donde se sumergieron las probetas elaboradas con la mezcla que tiene $15 \%$ de escoria, en peso, y superiores a 7,5 e inferiores a 10 en el agua de mar en donde han estado las restantes series de probetas fabricadas con las mezclas que tienen 35,60 y $70 \%$ de escoria, en peso; todo ello es consecuencia del $\mathrm{Ca}(\mathrm{OH})_{2}$ puesto en juego.

Las cantidades totales de $\mathrm{Ca}$ (II) en las fases disueltas $\mid \mathrm{Ca}$ (II) del agua de mar artificial ASTM + Ca (II) procedente de la disolución del $\mathrm{Ca}(\mathrm{OH})_{2}$ l de cada uno de los sistemas parciales - es decir, de cada serie de probetas fabricadas con una misma mezcla cemento $2 /$ escoria, sumergidas durante $56-90-180$ y 360 días en agua de mar artificial ASTM $(800 \mathrm{ml})$ junto con el correspondiente a las nuevas fases sólidas (tabla 1), se encuentran en el entorno representado en la figura 12, presentando los valores medios, para el conjunto de todas las edades, que se reseñan en la tabla 4 , en donde también se encuentran las cantidades de $\mathrm{Ca}$ (II) 
calculadas a partir del valor medio que corresponde al sistema parcial cemento 2 (100\%)-agua de mar artificial ASTM. Dichos valores se han representado en la figura 12. en donde se puede observar que son función de la cantidad de cemento 2 en las mencionadas mezclas, en las cuales existe un aporte de $\mathrm{Ca}$ (II). que hemos designado como aditivo. de tal modo que en la disolución más en la nueva fase sólida se encuentran las cantidades experimentales obtenidas en el caso de las probetas hechas con cemento $2\left(6,35 \times 10^{-2}\right.$ moles en $800 \mathrm{ml}$; valor medio $)$ sin adicion de escoria y cero moles cuando no existe cemento; fenómeno que se ha puesto de manifiesto en (7) y que se piensa comprobar experimentalmente en otros trabajos.

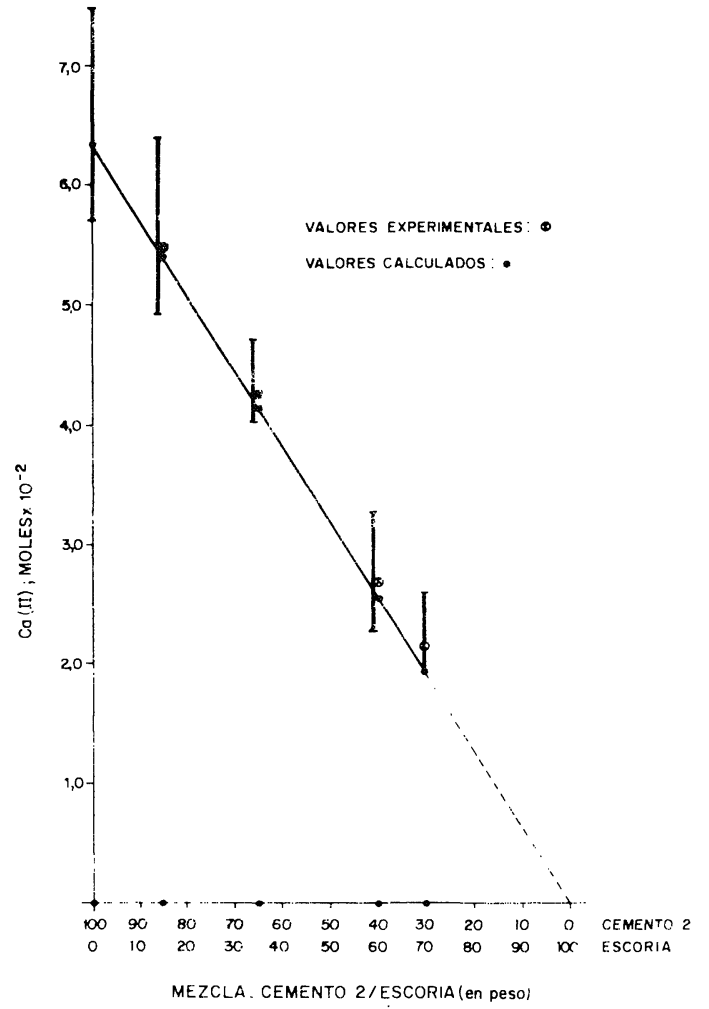

Fig. 12. Sistema: eemento 2/escoria-agua de mar artifi. cial ASTM. Fvolucion del contenido de Ca (II) total
TABLA 4

Sistema: cemento 2/escoria-agua de mar artificial ASTM. Cantidades de Ca (II) en la fase liquida y en la fase sólida: valores medios experimentales y calculados

\begin{tabular}{|c|c|c|}
\hline $\begin{array}{c}\text { Mezcla: } \\
\text { cemento 2 }\end{array}$ & \multicolumn{2}{|c|}{ Ca (II). moles $\times 1^{-2}$} \\
\cline { 2 - 3 } escoria & $\begin{array}{c}\overline{\mathbf{X}} \\
\text { experimental }\end{array}$ & $\begin{array}{c}\overline{\mathbf{X}} \\
\text { calculado }\end{array}$ \\
\hline $100 / 0$ & 6.35 & 6,35 \\
$85 / 15$ & 5,44 & 5,40 \\
$65 / 35$ & 4,23 & 4,13 \\
$40 / 60$ & 2,75 & 2,54 \\
$30 / 70$ & 2,20 & 1,91 \\
\hline
\end{tabular}

El $\mathrm{Ca}(\mathrm{OH})_{2}$, formado en las reacciones de hidratación de los compuestos del clinker. se ha detectado por DRX (3) en la fracción enriquecida extraida de las probetas de mortero hechas con cemento 2 sin adición de escoria y con las mezclas cemento $2 /$ escoria $=85 / 15$ y $65 / 35$

(en peso). En los casos restantes no se ha puesto de manifiesto, porque el $\mathrm{Ca}(\mathrm{OH})_{2}$ formado, en estado naciente, ha reaccionado parcialmente con la escoria y con el $\mathrm{CO}_{2}$ disuelto en el agua de mar para dar en la probeta los correspondientes compuestos de calcio y calcita. respectivamente: el resto se ha disuelto en el agua de mar artificial ASTM.

El $\mathrm{CO}_{2}$ disuelto en el agua de mar ASTM reacciona en medio básico fuerte con el Ca (II). que se encuentra en la fase disuclta, para dar carbonato de calcio, según (B):

$$
\mathrm{CO}_{2}+\mathrm{Ca}(\mathrm{II})+2 \mathrm{OH}(\mathrm{I}) \rightleftharpoons \mathrm{CaCO}_{3} \text {. sólido }+\mathrm{H}_{2} \mathrm{O}
$$

compuesto que ha precipitado como calcita y como aragonito. como se probo por DRX en (3), dando lugar a una nueva fase solida. produciendose. tambien. una disminucion de la concentracion de iones $\mathrm{OH}$ (I) y. por tanto, del valor del pH. Para que la reaceion (B) tenga lugar se tiene yue cumplir:

$$
\left|\mathrm{CO}_{3}(\mathrm{II})\right||\mathrm{Ca}(\mathrm{II})|>\operatorname{Ps}\left(4.8 \times 10^{\prime \prime}\right)
$$


teniendo en cuenta que:

$$
\mathrm{CO}_{2}+2 \mathrm{OH}(\mathrm{I}) \rightleftharpoons \mathrm{CO}_{3}(\mathrm{II})+\mathrm{H}_{2} \mathrm{O}
$$

El $\mathrm{Mg}$ (II) presente en el agua de mar artificial ASTM, a $\mathrm{pH}$ básico fucrte ( $\mathrm{pH}>10$ ). reacciona con los iones $\mathrm{OH}(\mathrm{I})$, según $(\mathrm{C})$ :

$$
\mathrm{Mg}(\mathrm{II})+2 \mathrm{OH}(\mathrm{I}) \rightleftharpoons \mathrm{Mg}(\mathrm{OH})_{2} \text {. sólido }
$$

por cumplirse:

$$
[\mathrm{Mg}(\mathrm{II})][\mathrm{OH}(\mathrm{I})]^{2}>\text { P's }\left(1,8 \times 10^{-11}\right)
$$

Esta reacción lleva consigo, como en el caso anterior, una disminución del $\mathrm{pH}$. En los medios $(800 \mathrm{~m} l$ de agua de mar artificial ASTM) en donde han estado sumergidas las probetas hechas con cemento 2 y con cemento $2 /$ escoria $=85 / 15$, con $\mathrm{pH} \geq 10$, se ha producido dicha reacción, habiéndose detectado el compuesto cristalino brucita en la fase sólida, en donde se encuentra el $\mathrm{Mg}$ (II) en cantidades $\geq$ a $0,5 \times 10^{-2}$ moles e inferiores a $1,8 \times 10^{-2}$ moles; en la fase liquida, prácticamente, ha desaparecido. El Mg (II) restante ha precipitado en el seno de las probetas de mortero como brucita (3), según (D):

$$
\mathrm{Mg}(\mathrm{II})+\underset{\text { probeta }}{\mathrm{Ca}(\mathrm{OH})_{2} \text { disuelto }} \rightleftharpoons \underset{\text { probeta }}{\mathrm{Mg}(\mathrm{OH})_{2} \text { sólido }}+\mathrm{Ca}(\mathrm{II})
$$

de tal modo que por cada mol de iones $\mathrm{Mg}$ (II) que ha precipitado, pasa al medio otro de $\mathrm{Ca}$ (II), el cual reacciona con los compuestos de la escoria o se encuentra en la disolución, o en la nueva fase sólida. Por el contrario, en los medios en donde han estado sumergidas las probetas de mortero fabricadas con las mezclas cemento $2 /$ escoria $=65 / 35,40 / 60$ y $30 / 70$ (en peso) no ha precipitado, el ion $\mathrm{Mg}$ (II), en la disolución por no darse las condiciones adecuadas ( $\mathrm{pH}$ comprendido entre 7,8 y 9,2); dicho ion se encuentra en la disolución en cantidades superiores a $0,1 \times 10^{-2}$ moles e inferiores a $2,5 \times 10^{-2}$ moles, el resto se encuentra en las probetas de mortero en donde ha penetrado por difusión y ha precipitado como brucita (3).

En la figura 13 se ha representado la evolución del contenido de los iones $\mathrm{Ca}$ (II) y $\mathrm{Mg}$ (II) en la disolución $\mathrm{Ca}$ (II) que procede del $\mathrm{Ca}(\mathrm{OH})_{2}$ disuelto $+\mathrm{Ca}$ (II) del agua de mar artificial ASTM| más en la nueva fase sólida, gráficas 1 y 3 , además del Ca (II) en la disolución más en la nueva fase sólida, que procede del $\mathrm{Ca}(\mathrm{OH})_{2}$ disuelto (sin tener en cuenta el $\mathrm{Ca}$ (II) del agua de mar artificial ASTM), gráfica 2, en función de la mezcla cemento 2/escoria utilizada para fabricar las diversas series de probetas de mortero para cada periodo de conservación-ataque; en dicha figura se aprecia que ambos contenidos están intimamente relacionados, de tal modo que existe un punto de cruce en las gráficas 2 y 3 , que corresponde a la mezcla cemento $2 /$ escoria $=40 / 60$, en peso, para todas las edades, en donde tiene lugar el siguiente equilibrio de intercambio iónico:

$$
\mathrm{Ca}(\mathrm{II}) \rightleftharpoons \mathrm{Mg} \text { (II) }
$$

(que pasa a la disolución) (que desaparece de la disolución)

que responde al equilibrio (D), según: 


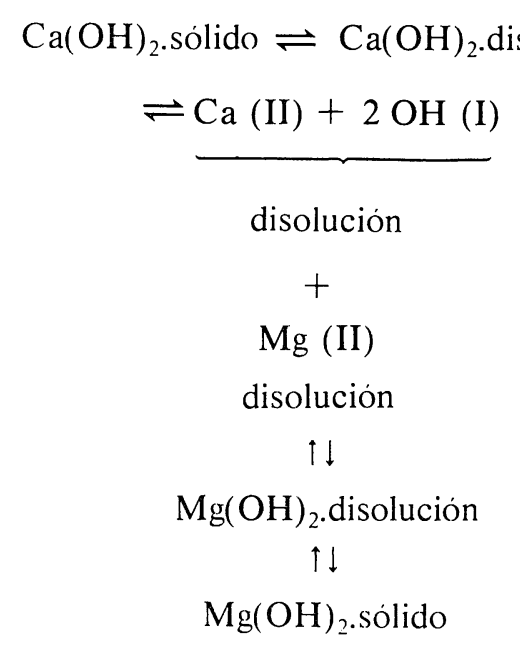

en donde por cada mol de iones $\mathrm{Ca}$ (II) puesto en juego desaparece otro de $\mathrm{Mg}$ (II). En los casos de las probetas hechas con mezclas que tienen cantidades inferiores al $60 \%$ de escoria, las cantidades de $\mathrm{Ca}$ (II) son superiores a las de $\mathrm{Mg}$ (II), ya que se genera más $\mathrm{Ca}(\mathrm{OH})_{2}$ durante la hidratación, quedando libre. en parte, mayor cantidad que facilita la precipitación del $\mathrm{Mg}$ (II) y la solubilidad del $\mathrm{Ca}(\mathrm{OH})_{2}$. Por el contrario, en los casos de las probetas fabricadas con mezclas que ticnen cantidades superiores de escoria ( $70 \%)$ se invierte el fenómeno, quedando en la disolución, más en la nueva fase sólida, contenidos mayores de $\mathrm{Mg}$ (II) que de $\mathrm{Ca}$ (II) por no darse las condiciones para que precipite el ion $\mathrm{Mg}$ (II), al no existir cantidad suficiente de iones $\mathrm{OH}$ (I), ya que no se ha generado la cantidad necesaria de $\mathrm{Ca}(\mathrm{OH})_{2}$. Los hechos mencionados influyen en el grado de resistencia quimica de los cementos.

La disminución que experimenta el contenido de iones $\mathrm{SO}_{4}$ (II) en el agua de mar artificial ASTM $\left(2,44 \times 10^{-2}\right.$ moles en $800 \mathrm{ml}$ para cada serie de probetas de mortero y edad) está intimamente ligada a las caracteristicas del cemento y de la escoria, asi como a la mezcla utilizada para fabricar las distintas series de probetas y al tiempo de conservación-ataque, que influyen en la formación de compuestos a base de sulfatos (yeso secundario y ettringita) en las probetas de mortero, como se probó por DRX (3), al reaccionar con los iones $\mathrm{Ca}(\mathrm{II})$, procedentes del $\mathrm{Ca}(\mathrm{OH})_{2}$, y con el aluminato de calcio hidratado del cemento según los equilibrios $(\mathrm{E})$ y $(\mathrm{F})$, respectivamente, por una parte:

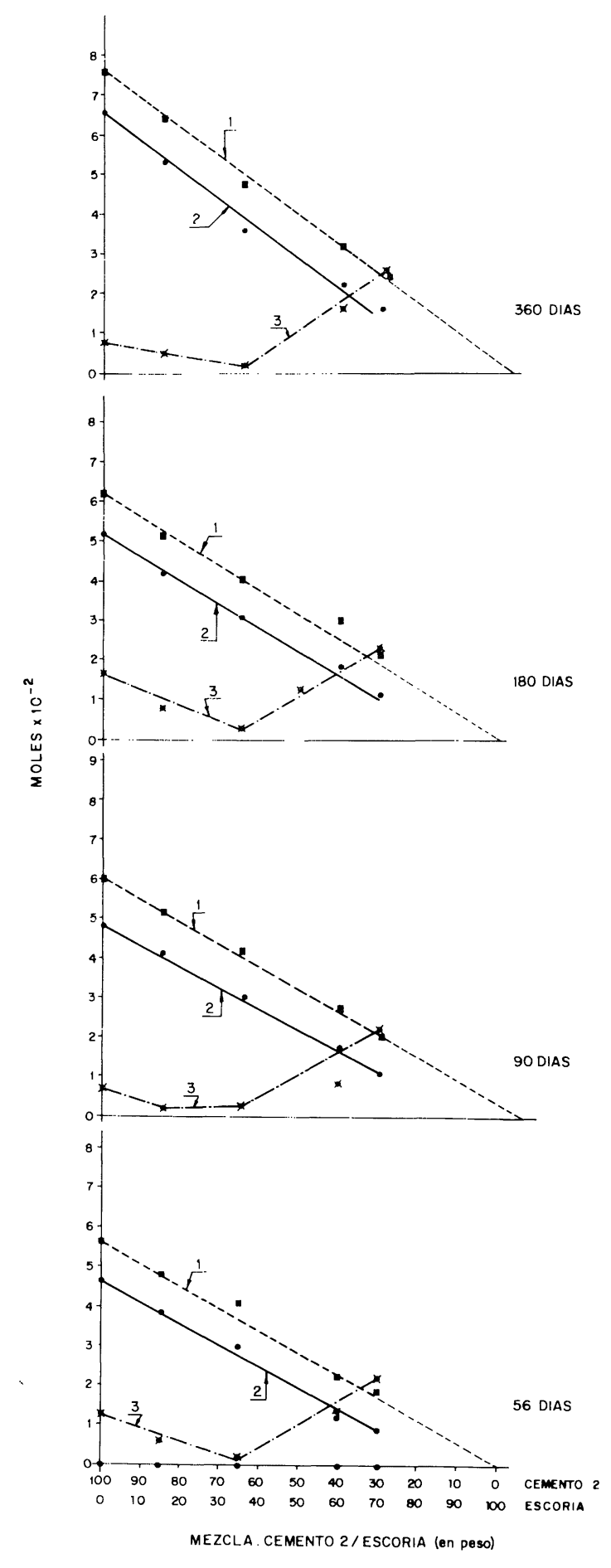

Fig. 13.- Sistema: cemento 2/escoria-agua de mar artificial ASTM. Evolucion de los contenidos de $\mathrm{Ca}$ (II) $\mathrm{y}$ de $\mathrm{Mg}$ (II).

Grafica $1=\mathrm{Ca}$ (II) en la disolucion $+\mathrm{Ca}$ (II) en la fase solida. $\mathrm{Ca}$ (II) en la disolucion = $\mathrm{Ca}$ (II) que procede del $\mathrm{Ca}(\mathrm{OH})_{2}$ disuelto $+\mathrm{Ca}(\mathrm{II}) \mathrm{del}$ agua de mar.

Cratica 2 -. (a (II) en la disolucion que procede del $\mathrm{Ca}(\mathrm{OH})_{2}$ disuelto $+\mathrm{Ca}$ (II) en la fase solida :- Ca (II) total disuclto.

Gráfica $3=\mathrm{Mg}$ (II) en la disolucion $+\mathrm{Mg}$ (II) en la fase sólida. 


$$
\mathrm{Ca}(\mathrm{II})+\mathrm{SO}_{4}(\mathrm{II})+2 \mathrm{H}_{2} \mathrm{O} \rightleftharpoons \mathrm{CaSO}_{4} \cdot 2 \mathrm{H}_{2} \mathrm{O}
$$

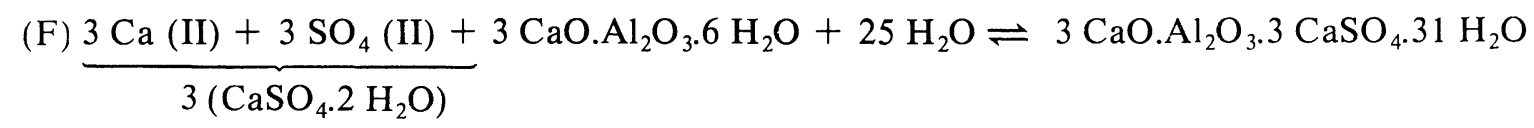

y con los aluminatos de la escoria y el $\mathrm{Ca}(\mathrm{OH})_{2}$ del cemento hidratado, por otra parte; equilibrio $(G)$ :

$$
\begin{aligned}
& \text { (G) } 2 \mathrm{CaO}^{2} \mathrm{Al}_{2} \mathrm{O}_{3} \\
& \quad \text { escoria vitrea }
\end{aligned}
$$

lo que hace que, para un clínker y una escoria dados, la cantidad de escoria en la mezcla influya en la cantidad de iones $\mathrm{SO}_{4}$ (II) fijados para formar ettringita; a veces, se presentan valores de la misma magnitud que en el caso de utilizar cemento 2 sin adición de escoria, como sucede en los sistemas parciales que corresponden a las series de probetas hechas con las mezclas que tienen 15 y $35 \%$ de escoria.

La disminución de iones $\mathrm{Cl}$ (I) del agua de mar artificial ASTM $\left(44,2 \times 10^{-2}\right.$ moles en $800 \mathrm{~m} l$ para cada serie de probetas de mortero y edad) se debe a la formación de la sal de Friedel en las probetas de mortero, por reacción de dichos iones $\mathrm{Cl}$ (I) con los iones $\mathrm{Ca}$ (II), que proceden del $\mathrm{Ca}(\mathrm{OH})_{2}$, y con los aluminatos de calcio hidratados o sus derivados. o con el $\mathrm{C}_{4} \mathrm{AF}$ o sus disoluciones sólidas, según $(\mathrm{H})$ :

$$
\text { (H) } \underbrace{2 \mathrm{Cl}(\mathrm{I})+\mathrm{Ca}(\mathrm{II})}_{\mathrm{CaCl}}+3 \mathrm{CaO} \cdot \mathrm{Al}_{2} \mathrm{O}_{3} \cdot 6 \mathrm{H}_{2} \mathrm{O}+4 \mathrm{H}_{2} \mathrm{O} \rightleftharpoons 3 \mathrm{CaO} \cdot \mathrm{Al}_{2} \mathrm{O}_{3} \cdot \mathrm{CaCl}_{2} \cdot 10 \mathrm{H}_{2} \mathrm{O}
$$

Del mismo modo que en al caso de los iones $\mathrm{SO}_{4}$ (II), la cantidad de iones $\mathrm{Cl}$ (I) eliminados depende. en este sistema, de la mezcla cemento 2/escoria utilizada en la fabricación de las diversas series de probetas de mortero y del tiempo de conservación-ataque; las mayores cantidades que han desaparecido de dichos iones corresponden, por regla general, al agua de mar artificial ASTM en donde han estado sumergidas las series de probetas elaboradas con las tres mezclas que tienen los mayores contenidos de escoria $(35,60$ y $70 \%$ en peso).

\section{CONCLUSIONES}

\section{Primera:}

En el agua de mar artificial ASTM (D 1141-75) en donde han estado sumergidas las diversas series de probetas de mortero $(1: 3)$, hechas con un cemento portland resistente al yeso (cemento 2) y con las mezclas cemento 2 /escoria estudiadas en este trabajo $(85 / 15,65 / 35,40 / 60$ y $30 / 70$, en peso), se produce un aumento de la concentración de iones $\mathrm{Ca}$ (II) y del valor del $\mathrm{pH}$, una disminución de la concentración de iones $\mathrm{Mg}$ (II), $\mathrm{SO}_{4}$ (II) y $\mathrm{Cl}$ (I), así como la formación de una nueva fase sólida, que son función de la mezcla utilizada para fabricar las mencionadas series de probetas y del tiempo de conservación-ataque.

\section{Segunda:}

La cantidad de fase sólida formada en los medios $(800 \mathrm{ml}$ de agua de mar artificial, por serie y por edad) en donde han estado sumergidas las diversas series de probetas, hechas con una misma mezcla, aumenta con el tiempo de conservación-ataque y disminuye, para una misma edad; según lo hace la cantidad de cemento en la mezcla utilizada para fabricar dichas probetas. 


\section{Tercera:}

El contenido de $\mathrm{Ca}$ (II) en la fase líquida más en la nueva fase sólida, que procede de un modo especial del $\mathrm{Ca}(\mathrm{OH})_{2}$ disuelto del cemento hidratado, para cada mezcla cemento 2/escoria utilizada en la fabricación de las distintas series de probetas de mortero, aumenta con el tiempo de conservación-ataque y, para cada edad, disminuye bruscamente conforme lo hace el contenido de cemento 2 de la mencionada mezcla.

Los valores medios de los contenidos totales de $\mathrm{Ca}$ (II) $[\mathrm{Ca}$ (II) que corresponde al agua de mar artificial ASTM + Ca (II) que se encuentra en la disolución y en la nueva fase sólida procedente del $\mathrm{Ca}(\mathrm{OH})_{2}$ disuelto] de cada conjunto de probetas elaboradas con cemento 2 y con las diversas mezclas cemento 2 /escoria para cada edad responde, prácticamente, a las cantidades teóricas, referidas al contenido de cemento 2 y calculadas a partir del valor medio del contenido total de Ca (II) del agua de mar artificial ASTM (800 ml), en donde han estado sumergidas cada serie de probetas hechas con dicho cemento 2 .

\section{Cuarta:}

El contenido de $\mathrm{Mg}$ (II) del agua de mar artificial ASTM, en donde han estado sumergidas las diversas series de probetas de mortero, experimenta una disminución que es función de la mezcla utilizada para fabricar las mencionadas series de probetas de mortero y del tiempo de conservación-ataque.

El ión $\mathrm{Mg}$ (II) ha desaparecido, prácticamente, de dicha agua de mar artificial en donde han estado sumergidas las diversas series de probetas de mortero hechas con cemento 2 y con la mezcla que tiene el menor contenido de escoria (15\%); en estos medios ha precipitado, parcialmente, como $\mathrm{Mg}(\mathrm{OH})_{2}$, al estado de brucita. En los casos restantes, dicho ion $\mathrm{Mg}$ (II), se encuentra en la fase liquida en cantidades diversas; en la nueva fase sólida se ha detectado en cantidades del orden de miligramos.

\section{Quinta:}

La evolución del contenido de Ca (II) está intimamente ligada con la del $\mathrm{Mg}$ (II), de tal modo que cuando el primero - $\mathrm{Ca}$ (II) - aumenta, el del segundo - $\mathrm{Mg}$ (II) - disminuye y viceversa. En este sistema existe un punto que corresponde al equilibrio iónico $\mathrm{Ca}$ (II) $\rightleftharpoons \mathrm{Mg}$ (II).

\section{Sexta:}

El contenido de $\mathrm{SO}_{4}$ (II) del agua de mar artificial ASTM, en donde han estado sumergidas las diversas series de probetas de mortero, experimenta una disminución que es más pronunciada en los medios correspondientes a las probetas de mortero hechas con cemento 2 y con las mezclas cemento 2 escoria $=85 / 15-65 / 35$ (en peso). En estos casos, el mencionado contenido de iones $\mathrm{SO}_{4}$ (II), disminuye conforme aumenta el tiempo de conservación-ataque.

\section{Séptima:}

El contenido de iones $\mathrm{Cl}$ (I) del agua de mar artificial ASTM, en donde han estado sumergidas las distintas series de probetas de mortero, experimenta una disminución (ligera), que es función de la mezcla cemento 2/escoria utilizada en la fabricación de dichas series de probetas y del tiempo de conservacion-ataque. Las mayores cantidades desaparecidas de dicho ión corresponden a los medios en donde han estado las series de probetas elaboradas con las tres mezclas que tienen los mayores contenidos de escoria $(35,60$ y $70 \%$, en peso). 


\section{BIBLIOGRAFIA}

(1) GASPAR-TEBAR, D. y SAGRERA MORENO, J. L. (1980): Resistencia quimica del hormigón: V. Acción del agua de mar: Influencia de la adición de escoria a un cemento portland resistente al yeso. Evolución de las resistencias mecánicas a flexotracción y del coeficiente de corrosión. Materiales de Construcción, julio-agosto-septiembre, 179, 59-79.

(2) SAGRERA-MORENO, J. L. y GASPAR-TEBAR, D. (1981): Resistencia quimica del hormigón: X. Influencia de la adición de escoria a un cemento portland resistente al yeso. Estudio por DRX del sistema cemento 2/escoria-agua potable filtrada. Materiales de Construcción, abril-mayo-junio, 182, 11-22.

(3) GASPAR-TEBAR, D. y SAGRERA-MORENO, J. L. (1982): Resistencia quimica del hormigon: XVIII. Acción del agua de mar: Influencia de la adición de escoria a un cemento portland resistente al yeso. Estudio por DRX. Materiales de Construcción, octubre-noviembre-diciembre, 188, 37-58.

(4) SAGRERA-MORENO, J. L. y GASPAR-TEBAR, D. (1984): Resistencia quimica del hormigón: XXIII. Influencia de la adición de escoria a un cemento portland resistente al yeso. Estudio de la concentracin iónica del sistema cemento 2/escoria-agua potable filtrada. Materiales de Construcción, abril-mayo-junio, 194, 43-51.

(5) GASPAR-TEBAR, D. y SAGRERA-MORENO, J. L. (1982): Resistencia quimica del hormigón: XVI. Acción del agua de mar: Influencia de la adición de escoria a un cemento portland de alta resistencia inicial. Estudio por DRX. Materiales de Construcción, abril-mayo-junio, 186, 39-60.

(6) BICZOK, J. (1972): Corrosion y Protección del Hormigón. Ed. Urmo. Bilbao, pág. 211

(7) GASPAR-TEBAR. D. y SAGRERA-MORENO. J. L. (1984): Resistencia quimica del hormigón: XXII. Influencia de la adición de escoria a un cemento portland de alta resistencia inicial. Estudio de la concentración iónica del sistema cemento 1/escoria-agua de mar artificial. Materiales de Construcción, enero-febrero-marzo, 193, 51-68.

\section{RECONOCIMIENTO}

Nuestro más sincero reconocimiento a las personas del Equipo de Durabilidad del IETcc: Amalia Rodriguez Pereira, Lucila López Solana, Felipe Cantero Palacios y Manuel Cantero Palacios por su valiosa colaboración en la realización de este trabajo.

\section{publicación del i.e.t.c.c.}

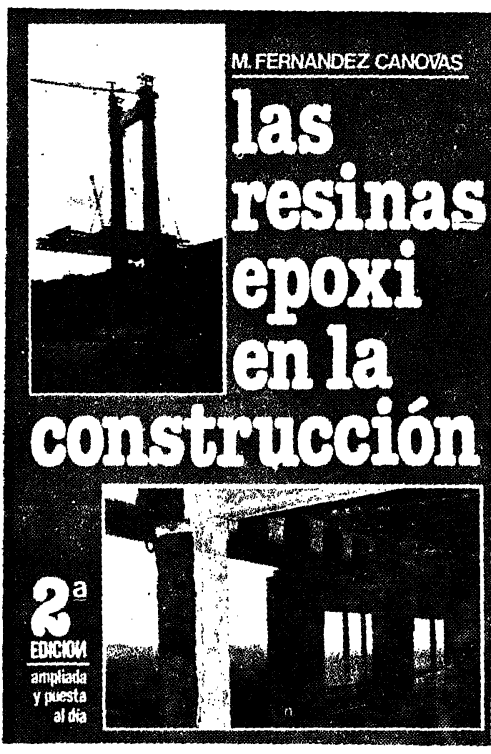

66
Manuel Fernández Cánovas

Dr. Ingeniero de Construcción

Este libro, el primero en lengua castellana sobre resinas epoxi aplicadas a la construcción, está dirigido a arquitectos, ingenieros, constructores y aplicadores. En él, sobre una reducida base teórica imprescindible, se asienta toda una extensa gama de aplicaciones de gran interés.

El autor trabaja desde hace muchos años en el campo de la investigación, especialmente en el estudio de refuerzos y reparaciones estructurales realizados con resinas epoxi.

Con un lenguaje sencillo se tocan todos los problemas que pueden presentarse en la construcción y en los que la solución puede radicar en el correcto empleo de las resinas epoxi.

Se estudian los componentes de las formulaciones epoxi, sus propiedades fisicas y quimicas, y aplicaciones, deteniéndose, detalladamente, en las siguientes:

Unión de hormigón fresco a hormigón endurecido. - Unión de hormigones entre si.-- Inyecciones de fisuras y grietas. - Unión de acero a hormigón. ... Barnices y pinturas. - Las combinaciones brea-epoxi. Revestimientos de depósitos alimenticios. -.. Sellado de superficies cerámicas. - Protección de tubos. - - Los suelos epoxi en sus diferentes variantes. -- Terrazo epoxi.-- Reparación de baches. - Reparación de desperfectos en estructuras. - Reparación de carreteras de hormigón. - - Juntas elásticas.--Guardacantos de tableros de puentes...-Refuerzos de pilares, vigas, forjados y zapatas, etc. - Consolidación de suelos. - Anclajes. - Protección de aceros en pretensado.

Se termina con unos capitulos dedicados a la limpieza y preparación de las superficies según los materiales a unir al control del estado superficial de éstos: a las condiciones de temperatura de aplicación: limpieza de los útiles de al control del estado superficial de éstos; a las condiciones de temperatura de aplicación; limpieza de los útiles de métodos de ensayo de sistemas y aplicaciones epoxidicas.

Un volumen encuadernado en cartoné plastificado con lomo de tela, de $17 \times 24 \mathrm{~cm}$, compuesto de 334 páginas y 158 figuras y fotografias.

Madrid, 1981

Precios: España, 1.700 ptas.; extranjero, \$ USA 34.00

MATERIALES DE CONSTRUCCCION VoI. 34, n*196, octubre/noviembre/diciembre 1984 